although it is the best therapeutic strategy in an acute setting.

\section{References}

1. Dake MD. Endovascular stent-graft management of thoracic aortic diseases. Eur J Radiol. 2001;39:42-9.

2. Eggebrecht H, Mehta RH, Dechene A, Tsagakis K, Kühl H, Huptas S, et al. Aortoesophageal fistula after thoracic aortic stent-graft placement: a rare but catastrophic complication of a novel emerging technique. JACC Cardiovasc Interv. 2009;2:570-6.
3. Vallabhajosyula P, Komlo C, Wallen T, Szeto WY. Two-stage surgical strategy for aortoesophageal fistula: emergent thoracic endovascular aortic repair followed by definitive open aortic and esophageal reconstruction. J Thorac Cardiovasc Surg. 2012;144:1266-8.

4. Coselli JS, Crawford ES. Primary aortoesophageal fistula from aortic aneurysm successful surgical treatment by use of omental pedicle graft. J Vasc Surg. 1990;12:269-77.

5. Riesenman PJ, Farber MA. Management of a thoracic endograft infection through an ascending to descending extra-anatomic aortic bypass and endograft explantation. J Vasc Surg. 2010;51:207-9.

\title{
Uterine leiomyoma extension into right atrium: A case report
}

\author{
Hua-shan Xu, MD, ${ }^{\mathrm{a}}$ Khan Mohammed Firoj, MM, ${ }^{\mathrm{a}}$ Kamran Yunus Inamdar, MM, ${ }^{\mathrm{b}}$ and \\ Wen-zeng Zhao, MM, ${ }^{\mathrm{a}}$ Zhengzhou and Urumchi, China
}

Uterine leiomyoma is a common disease in women; however, intravenous leiomyomatosis of uterine origin extending via inferior vena cava (IVC) into the right side of the heart, known as intracardiac leiomyomatosis (ICL), is a rare condition. Because of rarity, ICL is occasionally misdiagnosed as a right atrial myxoma and thrombus.

\section{CASE REPORT}

A 42-year-old married premenopausal woman complaining of intermittent vaginal bleeding was referred to our department for an intracardiac mass. She had a 1-month history of progressive breathlessness, fatigue on exercise, and edema of her lower extremities. Her echocardiogram revealed a large mass in the right atrium, and the mass extended via the IVC far into the pelvic vein (Figure 1), which was confirmed on magnetic resonance imaging (Figure 2). Because of unfamiliarity to the disease, it was diagnosed as right atrial myxoma, combined with longstanding IVC thrombosis. Later, pelvic ultrasonography revealed multiple leiomyomas of the uterus, which made the attention toward the diagnosis of ICL.

The patient underwent a 2-stage surgery. In the first stage (transatrial tumor resection), the operation was performed under normal temperature with establishment of

\footnotetext{
From the Department of Cardiovascular Surgery, ${ }^{a}$ Institute of Clinical Medical Research of Universities Henan, The First Affiliated Hospital of Zhengzhou University, Zhengzhou, Henan, China; and the Cardiovascular Surgery Department, ${ }^{\text {b }}$ The First Affiliated Hospital of Xinjiang Medical University, Urumchi, Xin Jiang, China.

Disclosures: Authors have nothing to disclose with regard to commercial support.

Received for publication April 13, 2013; accepted for publication May 2, 2013; available ahead of print June 28, 2013.

Address for reprints: Hua-shan Xu, MD, Department of Cardiovascular Surgery, The First Affiliated Hospital of Zhengzhou University, Zhengzhou 450052, Henan,

China (E-mail: xhsay@ hotmail.com).

J Thorac Cardiovasc Surg 2013;146:e13-4

$0022-5223 / \$ 36.00$

Copyright (c) 2013 by The American Association for Thoracic Surgery

http://dx.doi.org/10.1016/j.jtcvs.2013.05.003
}

cardiopulmonary bypass (CPB) by draining the blood from a single superior vena cava and recirculating back through the aortic root. The tumor mass was having a tailed-like structure invaded into the IVC (Figure 3), which was pulled out gently through the right atrial incision. Immediately after pulling out the mass, the IVC cannula was advanced into the IVC. The surgical views revealed that the tumor within the vessel and heart had no stalk and had well-demarcated borders with the wall of vessel and heart (Figure 3). Subsequently, the pathological report also confirmed uterine smooth muscle origin. So, oral tamoxifen ( $10 \mathrm{mg} / \mathrm{d}$, twice a day for 3 months) was administered. The second-stage surgery (hysterectomy) was done 2 weeks later for removing multiple uterine leiomyomas. In the recent 3 years of follow-up, she had no symptoms.

\section{DISCUSSION}

ICL is exceedingly rare. Most patients are usually premenopausal (median age, 44 years). A review of the literature reveals that more than half of the women with ICL had

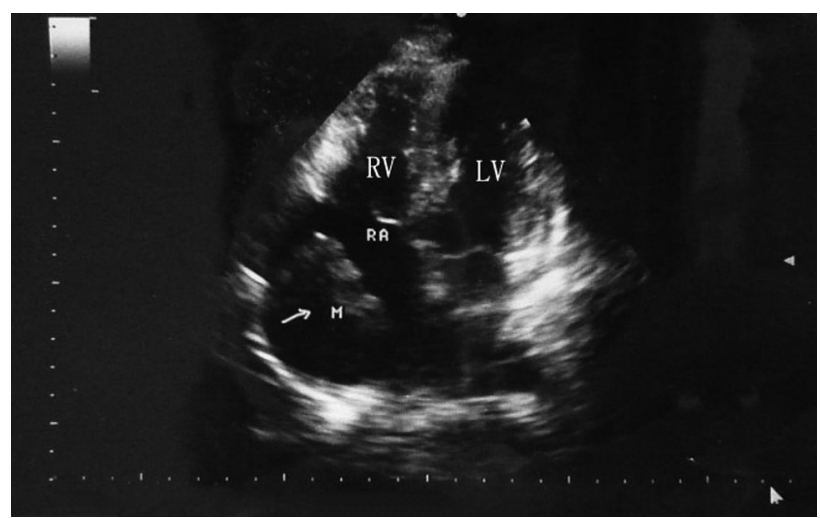

FIGURE 1. Apical 4-chamber view of echocardiography with a right atrial mass. $R V$, Right ventricle; $L V$, left ventricle; $R A$, right atrium; $M$, mass. 


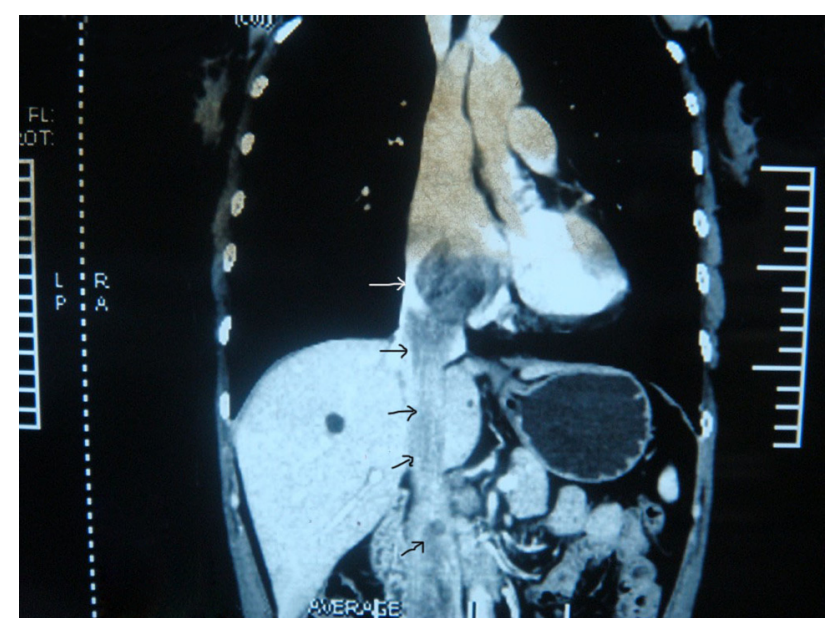

FIGURE 2. Magnetic resonance imaging showing extension of the tumor mass via inferior vena cava to the heart.

a history of hysterectomy. Imaging studies, such as ultrasonography, computed tomography, and magnetic resonance imaging, are useful investigations. Because of its nonspecific clinical presentation and rarity, ICL continues to be misdiagnosed as either thrombus or myxoma. The presence of a long, serpentine, and polypoidal mobile mass extending from the inferior vena cava into the right atrium should raise the suspicion of ICL.

Norris and Parmley ${ }^{1}$ proposed that the intravenous leiomyomatosis and ICL have 2 different origins, one is from uterine smooth muscle cells and the other is from the venous vessel itself; however, since the advent of immunohistochemical application on this disease, almost all cases had an estrogenic receptor on the smooth muscle cell surface.

Uterine leiomyomatosis is a systemic leiomyoma that metastasizes beyond the uterus. Many organs may be involved; other reported organs are the ovarian tube, ovary, peritoneum, spinal nerve, and even lungs. So, the principle of surgery is to first remove the intracardiac mass to prevent sudden death, and then to have a radical resection of the involved organ to prevent recurrence. Two different opinions concerned with surgery were adopted by surgeons. ${ }^{2-6}$ First, there was 1-stage surgery proposing concomitant thoracotomy and laparotomy. This adoption prevents recurrence, but obvious drawbacks of diffuse bleeding due to the extensive pelvic exploration after anticoagulation for $\mathrm{CPB}$ exist. So, we recommend 2-stage surgery. In the first stage, the tumor should be removed from the right atrium under CPB. The tumor coat is always smooth, so we infer that it does not have enough adhesions for tearing the vessels. The other problem is that the tumor may break at the far end of the tail because its small feet taking root into a small vein, which may result in recurrence. The second

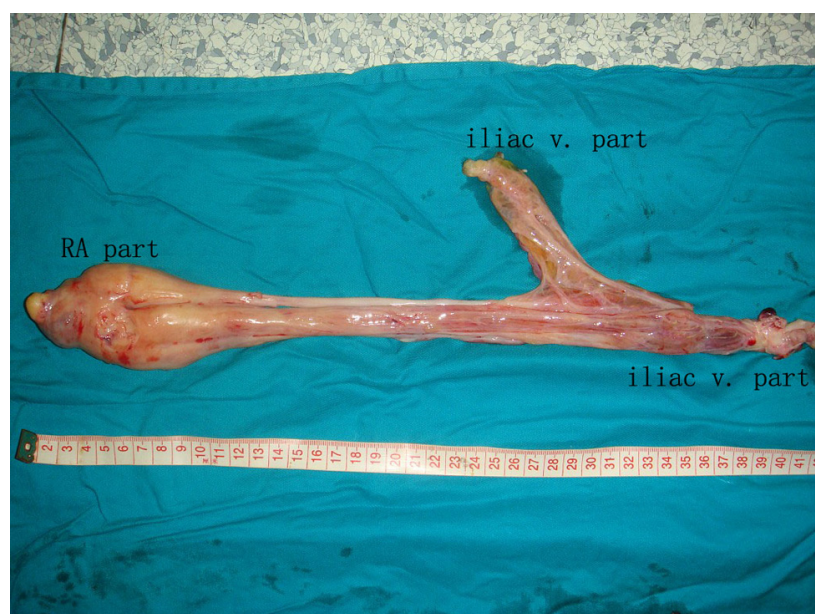

FIGURE 3. Tumor specimen extracted from the right atrium $(R A)$.

stage of a laparotomy surgery can be performed 2 weeks later when the systemic coagulation state and heart function return to normal. This permits an extensive exploration and resection of the involved organs without much worrying about the disaster of bleeding. Theoretically, the second surgery can be performed even earlier. The suitable interval between 2 surgical procedures remains to be studied and tried. We recommend shortening the interval, even though the patient is almost recovered.

On chemotherapy, Lo and $\mathrm{Lau}^{7}$ recommend that tamoxifen can be administered in patients who failed to undergo surgical treatment. Theoretically, the tumor cell can metastasize anywhere via blood flow and a suitable hormone concentration can flourish its growth. So, we recommend giving oral tamoxifen for at least 3 months postoperatively for subsiding the possible micrometastatic focus. The duration of drug treatment and its efficacy still remain to be studied.

\section{References}

1. Norris HJ, Parmley T. Mesenchymal tumors of the uterus, V: intravenous leiomyomatosis: a clinical and pathologic study of 14 cases. Cancer. 1975;36:2164-78.

2. Okada M, Miyoshi Y, Kato G, Ochi Y, Shimizu S, Nakai M. Successful one-stage surgical removal of intravenous leiomyomatosis with cardiac extension in an elderly patient. Gen Thorac Cardiovasc Surg. 2012;60:153-6.

3. Zhang T, Zhang XM, Shen CY, Li QL. Surgical strategies on intravenous leiomyomatosis invading heart [in Chinese]. Zhonghua Yi Xue Za Zhi. 2011;91:1957-60.

4. Lou YF, Shi XP, Song ZZ. Intravenous leiomyomatosis of the uterus with extension to the right heart. Cardiovasc Ultrasound. 2011;9:25.

5. Li Y, Mei F, Yang C, Lv P, Ouyang C, Jin B. Intravenous leiomyomatosis with right heart involvement: a report of 4 cases and literature review. J Huazhong Univ Sci Technolog Med Sci. 2011;31:586-8.

6. Li Q, Ma J, Hao B, Pi X, Li H. One-stage surgical removal of intravenous leiomyomatosis with right heart extension is safe. Heart Surg Forum. 2011;14:E192-4.

7. Lo KW, Lau TK. Intracardiac leiomyomatosis: case report and literature review. Arch Gynecol Obstet. 2001;264:209-10. 